\title{
Anatomia orientada para Pós-Graduação Lato Sensu em Enfermagem Obstétrica: experiência de uma gestação sem distocia
}

\author{
Fernando Batigália*
}

$\mathrm{Na}$ era globalizada da Farmacogenômica, da Epigenética e da Genômica Comparada e Funcional, o avanço científico tem se associado ao progresso tecnológico: tudo é exponencial e tende a ser efetuado rapidamente. Nesta avalanche de ideias e ideais que compóe a "geração Y”, o ensino e o aprendizado devem também se modernizar, ao se concentrarem menos na transmissão intensiva de informações, e mais em como a formação deve ser atualizada e eticamente elaborada.

Neste contexto, desde 2004, elaborou-se a disciplina de Anatomia Obstétrica no Curso de Pós-Graduação Lato Sensu em Enfermagem Obstétrica da Faculdade de Medicina de Sáo José do Rio Preto/SP (Enfobs/EspecialiZa/FAMERP). Objetivos incluem reforçar, atualizar, aplicar, adaptar e monitorar o aprendizado de conceitos e situaçóes em anatomia clínica ou cirúrgica da pelve, do períneo, do útero e da parede do abdome aplicados à vida profissional cognitiva, psicomotora e ético-atitudinal do enfermeiro obstétrico.

As aulas presenciais seguem uma dinâmica que prioriza a interação (por meio da preleção), o fluxo e a problematizaçáo de conceitos e de situaçóes clínicas ou cirúrgicas, com o devido respeito ao tempo necessário para a interiorizaçáo das ideias, para a adequada manutenção do aprendizado e para a permissão de criatividade. As avaliaçóes (presenciais e on-line) focam a capacidade do aluno em autogerenciamento e o seu grau de envolvimento ético-cognitivo.

A disciplina é estruturada por atividades em pré-aulas, aulas presenciais com atividades em grupo, atividades em pós-aulas, avaliaçóes (presenciais e on-line) e autogerenciamento. $\mathrm{O}$ material introdutório de todas as pré-aulas é imediatamente disponibilizado ao aluno, a fim de promover familiarização de conceitos por prévia revisão de conteúdos ao longo de todo o curso, a partir da seguinte disposição organizacional e dinâmica: anatomia clínica da pelve orientada para a Enfermagem, anatomia clínica do períneo orientada para a Enfermagem, anatomia da parede do abdome aplicada ao parto cesáreo e anatomia do desenvolvimento uterino orientada para a Enfermagem.

Existe monitoramento pedagógico, em que a avaliação de cada aluno tem sido efetuada a partir dos seguintes critérios de perfectibilização, em uma escala proporcionalmente cardinal de 0 a 10 , com aprovação mínima por média aritmética igual ou acima de 7 de um total de 14 
avaliaçóes formativas, a seguir: 50\% (envio das tarefas individuais on-line de pós-aula em tempo hábil e grau de coerência semântico-sintática nas respostas enviadas, a compor, assim, 4 avaliaçóes formativas individuais on-line de pós-aula); 17,5\% (grau de participação e de domínio cognitivo nas atividades individuais presenciais, a compor, assim, 4 avaliaçóes formativas individuais presenciais); 17,5\% (grau de participaçáo e de domínios cognitivo e psicomotor nas atividades em grupo, a compor, assim, 2 avaliaçóes formativas em Grupo); e 15\% (comportamento ético-atitudinal nos encontros presenciais e on-line, a compor, assim, 4 avaliaçóes formativas individuais ético-atitudinais presenciais).

O seguimento do grau de aprendizado de cada aluno tem sido estimado pela análise do valor absoluto de cada avaliaçáo formativa (de um total de 14), e serve de escopo para discussóes com o corpo discente e com a equipe de implementação tecnológica para análise crítica da eficácia das habilidades, competências, estratégias de ensino, conteúdo e tecnologias adotadas.

Depois de decorrida mais da metade do período de tempo estimado para término da disciplina, há disponibilização on-line de questionário referente ao grau de satisfação de cada aluno quanto à estruturação física, organizacional e pedagógica do curso. A expressão gráfica de estimativa do grau de aprendizado de cada aluno, a partir dos valores absolutos obtidos em cada avaliação formativa, tem sido efetua- da por meio da elaboraçáo de histogramas de barras, e percentagens de respostas referentes ao questionário preenchido individualmente sobre grau de satisfação quanto à estruturação física, organizacional e pedagógica do curso são também representadas graficamente por meio de histogramas de barras.

Ao término do curso, ambos os gráficos são comparados para análise crítica final das políticas educacionais adotadas, e desde 2006 existe a entrega do CD-ROM "Anatomia Obstétrica orientada para a Enfermagem", elaborado pela equipe pedagógica.

Ao permitirmos que o aluno se sinta bem-vindo para aprender a crescer pela aplicação da associação de ideias, no âmbito da inteligência emocional, "frutos" deste imenso esforço têm sido colhidos: oito anos consecutivos de Curso, com profissionais contratados em hospitais das cidades de São Paulo e Ribeirão Preto, e ex-alunos como professores no próprio Curso. Neste processo contínuo de iniciação, motivação, assimilação e finalização de profissionais em Anatomia Obstétrica, deixamos aqui nosso exemplo, e convidamos todos os profissionais de Saúde a transformar informaçâo infinita disponivel em informação essencial interiorizada, para que o juízo ético seja sempre capaz de harmonizar inovaçóes tecnológicas e métodos de aprendizado, sem perder o humanismo que caracteriza os fundamentos do processo de estar e, principalmente, de ser enfermeiro. 